Original Research Article

\title{
To evaluate the anti-inflammatory activity of ramipril in albino rats
}

\author{
Siddamma Amoghimath ${ }^{1 *}$, Suresha R. N.², Jayanthi M. K. ${ }^{2}$
}

${ }^{1}$ Department of Pharmacology, Gadag Institute of Medical Sciences, Gadag, Karnataka, India

${ }^{2}$ Department of Pharmacology, JSS Medical College and Hospital, Mysuru, Karnataka, India

Received: 12 November 2017

Revised: 14 November 2017

Accepted: 24 November 2017

*Correspondence to:

Dr. Siddamma Amoghimath,

Email: siddama.a@gmail.com

Copyright: (C) the author(s), publisher and licensee Medip Academy. This is an openaccess article distributed under the terms of the Creative Commons Attribution NonCommercial License, which permits unrestricted noncommercial use, distribution, and reproduction in any medium, provided the original work is properly cited.

\begin{abstract}
Background: Angiotensin II (Ang II) is a product of Renin angiotensin aldosterone system (RAAS). Angiotensin-II regulates vascular tone, stimulates the release of pro-inflammatory cytokines, activates nuclear factor-kappa B $(\mathrm{NF}-\mathrm{\kappa B})$, increases oxidant stress and functions as an inflammatory molecule. Ramipril an ACE inhibitor act by inhibiting angiotensin converting enzyme, decreases angiotensinogen II activity. Hence the present was to evaluate the antiinflammatory activity of Ramipril.

Methods: Eighteen Wistar albino rats weighing around 150-200gms of either sex were randomly selected from central animal facility and divided into three groups. The control group received normal saline $25 \mathrm{ml} / \mathrm{kg}$, standard group received Indomethacin $10 \mathrm{mg} / \mathrm{kg}$ and test group received Ramipril $(0.9 \mathrm{mg} / \mathrm{kg})$ orally for six days. The animals were subjected to carrageenan induced paw oedema and cotton pellet induced granuloma model.

Results: Ramipril significantly decreased the mean paw oedema in carrageenan induced paw oedema when compared to control and in cotton pellet induced granuloma Ramipril decreased the mean granuloma weight when compared to control.

Conclusions: Ramipril showed anti-inflammatory activity when given for 6 consecutive days per orally in albino rats in carrageenan induced paw oedema and cotton pellet induced granuloma model.
\end{abstract}

Keywords: Angiotensin II, Carrageenan, Cotton pellet, NF- $\kappa \beta$, ROS

\section{INTRODUCTION}

Inflammation is the final common pathway of various insults, such as infection, trauma, and allergies to the human body. It is a complex reaction in vascularised connective tissue due to exogenous /endogenous stimuli. Inflammation is fundamentally a protective response the ultimate goal of which is to rid the organism of both initial cause of cell injury and its consequences. ${ }^{1}$ Pain is often associated with inflammation. Inflammation is a normal response to any noxious stimulus that threatens the host and may vary from localized response to a generalized one. It is a complex process involving release of chemicals from tissues and migrating cells and various mediators such as prostaglandins, leukotrienes and platelet activating factors.
Tissue injury induces a series of reactions with the release of pro inflammatory cytokines such as TNF- $\alpha$, IL- $\beta$, IL- 6 . IL- 8 , followed by subsequent inflammatory reactions. In inflammatory disease like Rheumatoid arthritis, the inflamed tissue produces elevated levels of prostaglandins such as PGE1 and PGE2, increase local blood flow and potentiate the effect of mediators like bradykinin that cause increased vascular permeability. ${ }^{2}$

Angiotensin II (Ang II) is a key product of Renin angiotensin aldosterone system (RAAS). Angiotensin-II regulates vascular tone, stimulates the release of pro-inflammatory cytokines, activates nuclear factor-kappa B (NF- $\mathrm{KB})$, increases oxidant stress and functions as an inflammatory molecule. ${ }^{3}$ Ang II initiates 
the inflammatory process by the release of reactive oxygen species (ROS). ROS activates the NF- $\kappa \beta$, which in turn increases transcription of pro inflammatory cytokines, adhesion molecules and NADPH molecules. Ang II also increases the transcription of monocyte chemotactic protein-1(MCP-1), macrophage colony stimulating factor (M-CSF), endothelial selectin (E-selectin), intercellular adhesion molecule-1 (ICAM-1), vascular cell adhesion molecule -1(VCAM-1), inducible nitric oxide synthase, cyclooxygenase-2. ${ }^{4-6}$ Angiotensin-II enhances ROS production by activating NADPH oxidase and stimulates the DNA-binding activity of NF- $\kappa \mathrm{B}$ in human neutrophils. Tissue levels of $\mathrm{NF}-\kappa \mathrm{B}$, results in inflammatory cell infiltration. ${ }^{7}$ Angiotensin-II increases the synthesis and concentration of tumour necrosis factor- $\alpha$ (TNF- $\alpha$ ), interleukin-6 (IL6), and chemokine monocyte chemo attractant protein-1. Ang II supresses PPAR- $\alpha$ and PPAR$\gamma$. Increase ACE activity leads to high levels of Ang II. High levels of Ang II activated NADPH which in turn leads to enhanced formation of ROS and decreased nitric acid levels. ${ }^{8}$

Angiotensin converting enzyme inhibitors like Ramipril act by inhibiting angiotensin converting enzyme, decreases angiotensinogen II activity and increases the bradykinin and (met) enkephalin. ACE inhibitors are commonly used in the treatment of hypertension, heart failure, diabetic nephropathy, nondiabetic renal disease and post myocardial infarction.

Hypothesis: Hence it is hypothesized that Ramipril mediate anti-inflammatory effect via reducing the action of Angiotensin II.

\section{METHODS}

The study was conducted after the approval of IAEC (Institutional Ethical Committee). Adult healthy albino rats of Wistar strain of either sex, weighing between 200250gm aged 3-4 months were selected from the Central animal facility. The rats were inbred in the central animal house, under suitable conditions of housing, temperature, ventilation and nutrition. Rats were housed two to three per stainless cage under conventional conditions. They were kept at a constant temperature of $26 \pm 2^{\circ} \mathrm{C}$ and relative humidity of $30-70 \%$ under a $12 \mathrm{~h}$ dark/light cycle. The animals were fed with standard diet and water ad libitum. The rats were acclimatized to the laboratory conditions for seven days prior to test before assigning animals to treatment group. The doses of drugs were based on human daily dose converted to that of rats according to Paget and Barnes (1962).

\section{Drugs and Chemicals}

Indomethacin (Sun Pharmaceutical Industries Ltd., India), Ramipril (Cipla, India), Carrageenan (TCI Chemicals, India), Vernier calliper purchased from Precision India Ltd. The rats were divided into 3 groups containing six animals $(n=6)$ in each group (control, standard and test group).

- Group-1 (Control): Normal saline $25 \mathrm{ml} / \mathrm{kg}$

- Group-2 (Standard): Indomethacin $10 \mathrm{mg} / \mathrm{kg}$

- Group-3 (Test 1): Ramipril (0.9mg/kg)

\section{Carrageenan induced rat paw oedema $a^{9,10}$}

One hour after the drug administration, paw oedema was induced by injecting $0.1 \mathrm{ml}$ of $1 \%$ carrageenan into sub plantar tissue of the right hind paw of each rat of each group. The right hind paw volume will be measured immediately by using the vernier calliper (zero - hourvolume) and at the end of 4 hours. The mean paw oedema in each group of animals treated with drugs groups and control group were noted. The anti-inflammatory activity was calculated as percentage inhibition of oedema in the animals treated with Ramipril in comparison to the carrageenan control group.

The percentage (\%) inhibition of oedema is calculated using the formula

$$
\text { Percentage Inhibition }=\frac{V c-V t}{V t} X 100
$$

Where, Vc is paw volume in control; Vt is paw volume in test drug

\section{Cotton wool pellet induced granulomas ${ }^{11}$}

Cotton pellets weighing $10 \pm 1 \mathrm{mg}$ were sterilized in an autoclave for 30 minutes $120^{\circ} \mathrm{C}$. One hour after the drug administration on first day, under mild ether anaesthesia 4 incisions were made in both axilla and groins. Four pellets were implanted subcutaneously into the ventral region, two on either side. Cotton wool pellets were introduced in it and sutured back with a black silk. Later drugs will be administered once a day for 6 consecutive days. On $8^{\text {th }}$ day the animals were anaesthetised using ether and the pellets together with the granuloma tissue were carefully removed. The wet pellets were weighed for the determination of the wet weight and then dried in an incubator at $60^{\circ} \mathrm{C}$ for $18 \mathrm{~h}$ until a constant weight is obtained and then the dried pellets were weighed to determine the constant dry weight.

Exudate amount $(\mathrm{mg})=$ Wet weight of pellet- Constant dry weight.

Granulation tissue formation $(\mathrm{mg})=$ Constant dry weightWeight of the cotton pellet (10mg).

\section{Statistical analysis}

The results were analysed by calculating- mean, standard deviation, t-test and analysis of variance (ANOVA) at different time intervals within the same group, followed by independent sample t-test between the two groups. One- 
way ANOVA was used for multiple group comparisons followed by post hoc Tukey's test for statistical significance between groups. IBM SPSS statistics ${ }^{\odot}$ IBM Corporation and Other(s) 1989, 2012 software was used for statistical analysis purpose. $\mathrm{P}<0.05$ was considered as significant.

\section{RESULTS}

Table 1 Shows the effect of Ramipril and Indomethacin drug in carrageenan induced paw oedema using vernier callipers.

Table 1: Effect of Ramipril and Indomethacin as compared to control group at different hour in carrageenan induced paw oedema using vernier calliper.

\begin{tabular}{|c|c|c|c|c|}
\hline \multirow[b]{2}{*}{ Groups } & \multirow[b]{2}{*}{ Dose } & \multicolumn{3}{|c|}{ Change in paw oedema $(\mathrm{cm})$} \\
\hline & & $\begin{array}{l}\text { Mean paw } \\
\text { oedema }(0 \text { hr. })\end{array}$ & $\begin{array}{l}\text { Mean paw oedema } \\
\text { (4 hr.) }\end{array}$ & $\begin{array}{l}\text { Difference in mean } \\
\text { paw oedema }\end{array}$ \\
\hline Control & $25 \mathrm{ml} / \mathrm{kg}$ & $1.48 \pm 0.10$ & $11.3 \pm 0.48$ & $9.85 \pm 0.38$ \\
\hline Indomethacin & $10 \mathrm{mg} / \mathrm{kg}$ & $1.20 \pm 0.07$ & $5.19 \pm 0.26$ & $3.99 \pm 0.19$ \\
\hline Ramipril & $0.9 \mathrm{mg} / \mathrm{kg}$ & $1.46 \pm 0.14$ & $7.03 \pm 0.69$ & $5.57 \pm 0.55^{*}$ \\
\hline
\end{tabular}

The values are expressed as Mean $\pm \mathrm{SD}$, where $\mathrm{n}=6$ rats, $* \mathrm{p}$ value $<0.05$

Ramipril at the dose of $0.9 \mathrm{mg} / \mathrm{kg}$ per orally prevented carrageenan induced paw oedema with the percentage inhibition of $43.45 \%$, while, Indomethacin at the dose of $10 \mathrm{mg} / \mathrm{kg}$ per orally produced $59.49 \%$ when compared to control.

Table 2 Shows the effect of Ramipril and Indomethacin drug as compared to control in cotton pellet induced granuloma model. Mean weight of granuloma of Ramipril is $52.72 \mathrm{mg}$ less when compared to control, and Indomethacin group showed $75.51 \mathrm{mg}$ less compared to control.

\section{Table 2: Mean granuloma weight in all treated groups.}

\begin{tabular}{|lll|}
\hline Groups & Dose & $\begin{array}{l}\text { Mean weight of } \\
\text { granuloma (mg) } \\
\text { (Mean } \pm \text { SD) }\end{array}$ \\
\hline Control & $25 \mathrm{ml} / \mathrm{kg}$ & $130.33 \pm 3.37$ \\
\hline Indomethacin & $10 \mathrm{mg} / \mathrm{kg}$ & $54.82 \pm 2.72$ \\
\hline Ramipril & $0.9 \mathrm{mg} / \mathrm{kg}$ & $77.61 \pm 1.43^{*}$ \\
\hline
\end{tabular}

The values are expressed as Mean \pm SD where $n=6$ rats, *p value $<0.05$.

\section{DISCUSSION}

Carrageenan induced rat paw oedema is the suitable model to screen acute inflammation. The accumulation of paw oedema is biphasic. The first phase begins immediately after the injection of carrageenan and diminishes in an hour. The mediators of inflammation in the first phase is histamine and 5-HT. The second phase is related to release of prostaglandins, begins at the end of first hour and persist through the $3^{\text {rd }}$ hour. The first phase accounts for $40 \%$ of the total oedema volume. Table 1 Shows at the end of 4 hours the mean difference of paw oedema is $9.85 \mathrm{~cm}$ of control, $3.99 \mathrm{~cm}$ of Indomethacin and $5.57 \mathrm{~cm}$ of test drug Ramipril. The carrageenan induced paw oedema model is used to evaluate the effect of non-steroidal antiinflammatory agents because it inhibits the cyclooxygenase pathway. As shown in Table 1 There is significant $(\mathrm{p}<0.05)$ percentage inhibition of paw oedema of Ramipril group is $43.45 \%$ when compared to control.

In cotton pellet induced granuloma there are three phases, a transudative phase during the first 3 hours, exudative phase between 3 to 72 hours and proliferative phase between 3 to six days. Indomethacin at the dose of $10 \mathrm{mg} / \mathrm{kg}$ showed the mean granuloma weight of $54.82 \mathrm{mg}$ and Ramipril at the dose of $0.9 \mathrm{mg} / \mathrm{kg}$ showed the mean granuloma weight of $77.61 \mathrm{mg}$. When compared to control the percentage decrease in granulation tissue formation of Ramipril is $40.45 \%$ and that of Indomethacin is $57.93 \%$. Table 2 shows there is significant $(\mathrm{p}<0.05)$ decrease in mean granuloma weight of Ramipril when compared to control.

The above findings indicate that Ramipril acts as an antiinflammatory drug in albino rats. ${ }^{12}$ Carrageenan induced rat paw edema and cotton pellet induced granuloma method are used to assess the inflammatory activity of Ramipril.

\section{CONCLUSION}

The test drug Ramipril showed significant decrease in mean paw edema and mean granuloma weight when compared to that of control. The anti-inflammatory activity justifies the hypothesis stated above. Thus, to conclude Ramipril showed the anti-inflammatory activity in albino rats by decreasing the Ang II, which in turn decreases the reactive oxygen species (ROS) and nuclear factor-kappa B (NF- $\kappa \mathrm{B})$.

\section{ACKNOWLEDGEMENTS}

Authors would like to thank our institution for permitting and providing the necessary assistance for the study.

Funding: No funding sources

Conflict of interest: None declared 
Ethical approval: The study was approved by the Institutional Ethics Committee

\section{REFERENCES}

1. Kumar V. Robbins Basic Pathology. In: Kumar V, Abbas AK, Aster JC. Acute and chronic inflammation. New Delhi: Saunders; 2013:29-40.

2. Katzung BG. Basic and Clinical Pharmacology. In: Furst DE, Ulrich RD, Altamirano CV. Non-steroidal anti-inflammatory drugs. Mumbai: McGraw hill; 2009:181-185.

3. Ortega RM, Ruprez M, Lorenzo O, Esteban V, Blanco $\mathrm{J}$, Mezzano S, et al. Angiotensin II regulates the synthesis of proinflammatory cytokines and chemokines in the kidney. Kidney Intl. 2002;82:1222.

4. EL Bekay R, Alvarez M, Monteseirin A, Alba G, Chacon P, Vega A, et al. Oxidative stress is a crutial mediator of the angiotensin II signal in human neutrophils of mitogen activated protein kinase, calcineurin and the transcription factor NF- $\kappa \beta$. Blood. 2003;102:662-71.

5. Tham DM, Martin McNulty B, Wang YX, Wilson DW, Vergona R, Sullivan M E, et al. Angiotensin II is associated with activation of NF- $\kappa \beta$ - mediated genes and downregulation of PPARs. Physiol genomics. 2002;11:21-30.

6. Pueyo ME, Gonzalez W, Nicoletti A, Savoie F, Amal J F, Michel J B. Angiotensin II stimulates endothelial cell adhesion molecule I via NF- $\kappa \beta$ activation induced by intracellular oxidative stress. Arterioscler Thromb Vasc Biol. 2000;20:645-51.

7. Das UN. Angiotensin-II behaves as an endogenous pro-inflammatory molecule. J Assoc Physicians India. 2005;53:472-6.

8. Hayek T, Pavlotzky E, Hamound S, Coleman R, Keidar S, Aviram M, et al. Tissue angiotensin converting enzyme (ACE) deficiency leads to a reduction in oxidative stress and in atherosclerosis. Arteriosclerosis Thromb Vasc Biol. 2003;23:2090-96.

9. Winter CA, Porter CC. Effect of alteration in side chains upon anti-inflammatory and liver glycogen activities in hydrocortisone ester. J Am Pharmacol Soc. 1957;46:515-9.

10. Di Rosa M, Giroud JP, Willoughby DA. Studies on the mediators of the acute inflammatory response induced in rats in different sites by carrageenan and turpentine. J Pathol. 1971;104:15-29.

11. Leme JG, Hamamura L, Leite MP, Silva MR. Pharmacological analysis of the acute inflammatory process induced in the rat's paw by local injection of carrageenin and by heating. $\mathrm{Br} \mathrm{J}$ Pharmacol. 1973;48:88-96.

12. El-Shenawy S. Effect of ramipril, valsartan and candesartan on thermal and visceral pain in mice. $\mathbf{J}$ Pharmacol and Toxicol. 2007;2(6):533-41.

Cite this article as: Amoghimath $\mathrm{S}$, Suresha RN, Jayanthi MK. To evaluate the anti-inflammatory activity of ramipril in albino rats. Int $\mathrm{J}$ Basic Clin Pharmacol 2018;7:16-9. 